\title{
Activación de resistencia sistémica inducida en vid "Thompson Seedless", en respuesta Pseudomonas veronii R4
}

\author{
Activation of induced systemic resistance in grapevine "Thompson Seedless", response \\ Pseudomonas veronii R4
}

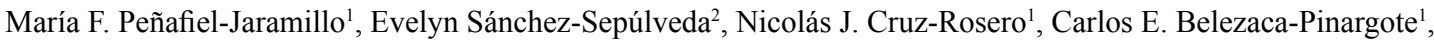
Humberto G. Prieto-Encalada ${ }^{2},{ }^{\circ}$ Hayron F. Canchignia-Martínez ${ }^{3}$

${ }^{1}$ Facultad de Ciencias Ambientales, Escuela de Gestión Ambiental, Universidad Técnica Estatal de Quevedo. Campus Manuel Haz Álvarez. Av. Quito Km 1.5 vía Santo Domingo de los Tsachilas. EC.120501.Quevedo, Ecuador. mariapenafielj@gmail.com; jcruz@uteq.edu.ec; cbelezaca@uteq.edu.ec

${ }^{2}$ Laboratorio de Biotecnología, Instituto de Investigaciones Agropecuarias, Estación La Platina. Santa Rosa 11610. La Pintana, Santiago,Chile.Código postal 8831314. evelyn.sanchez.s@gmail.com; hprieto@inia.cl

${ }^{3}$ Laboratorio de Microbiología Ambiental y Vegetal, Facultad de Ciencias Agrarias, Escuela de Agronomía, Universidad

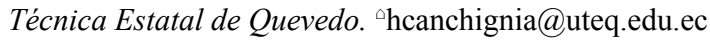

Resumen

$E^{1}$ l objetivo principal fue evaluar el mecanismo de RSI en "Thompson Seedless", al estímulo de los genes (Lox2, Tlp1, Npr1, Eir1). Se verificaron la activación de genes de defensa para hojas y raíces, demostrando la activación sistémica por inoculación de $P$. veronii $\mathrm{R} 4$ en 'Thompson Seedless'. Mediante q-PCR observamos la expresión del gen Lox2 en hojas de vid, con aumento progresivo hasta (12 h de post inoculación) de muestreo, al analizar este mismo gen en raíces no existió estímulo alguno. Los niveles transcripcionales de los genes Eirl y Tlp1, fueron estimulados solo en raíces al ser expuestas por R4. Los niveles de estímulo del gen Tlp1 se relaciona con la habilidad que tiene $\mathrm{R} 4$ en desarrollar el complejo de simbiosis inducido por la vía del etileno (ET). Los niveles de estímulo del gen $\mathrm{Nprl}$ fueron constitutivos en hojas y raíces, no encontrando diferencias significativas entre plantas tratadas con PBS o R4. Los resultados demuestran que R4, en contacto con raíces de 'Thompson Seedless', estimulan la expresión de los genes Eir1, Lox2, Tlp1 a 5 min, 6 y 12 h de post inoculación, permitiendo establecer la efectividad de RSI dirigida por la cepa R4 en "Thompson Seedless" confiriendo un estado de prealerta.

Palabras clave: : ácido salicílico, Arabidopsis thaliana, jasmonato, Vitis vinífera

Recibido: 23-junio-2015. Recibido en forma corregida: 17-noviembre-2015. Aceptado: 28-enero-2016.

Publicado como ARTÍCULO CIENTÍFICO en Ciencia y Tecnología 9(1): 1-9 Junio de 2016

\begin{abstract}
$\mathrm{T}$ he main objective was to evaluate the mechanism of RSI to "Thompson Seedless" for stimulus (Lox2, Tlp1, Npr1, Eir1) genes. Activation of defense genes for leaves and roots were checked, showing the systemic activation by inoculation of $P$. veronii $\mathrm{R} 4$ in 'Thompson Seedless'. Observed by q-PCR gene expression Lox2 in vine leaves with progressive increase up (12 h post inoculation) sampling, analyzing this same gene in roots did not exist any stimulus. The transcriptional levels of genes Tlp1 Eirl and were stimulated only in roots when exposed to R4. Stimulus levels Tlp1 relates gene having R4 skill in symbiosis develop complex induced via the ethylene (ET). Stimulation levels were constituent $\mathrm{Nprl}$ gene in leaves and roots, with no significant differences between plants treated with PBS or R4. The results show that R4, contact roots of 'Thompson Seedless', stimulate the expression of Eir1, Lox2, Tlp1 genes to $5 \mathrm{~min}, 6$ and $12 \mathrm{~h}$ post inoculation, allowing establish the effectiveness of RSI strain led R4 in "Thompson Seedless" giving a state of pre-alert.
\end{abstract}

Key words: alicylic acid, Arabidopsis thaliana, jasmonate, Vitis vinifera 


\section{Introducción}

$V_{\text {anion }}$ tis vinifera es una especie frutal que se encuentra ampliamente distribuida en el mundo, sin embargo, su producción anual superior a 60 millones de toneladas de uvas, presenta grandes desafíos, por la presencia de patógenos, desde la etapa de vivero, hasta la post-cosecha (Kortekamp, 2006). Existen suelos agrícolas que conservan una variabilidad de micro-ecosistema, capaces de regular problemas fitopatológicos, por la presencia de rizobacterias que promueven el crecimiento en plantas (PGPR). Se ha reportado bacterias con estas características de los géneros: Azoarcus, Azospirillum, Azotobacter, Arthrobacter, Bacillus, Clostridium, Enterobacter, Gluconoacetobacter, Pseudomonas (Somers y Srinivasan, 2004).

Las plantas han desarrollado varios mecanismos de adaptación como respuesta a fluctuaciones medioambientales (Parker et al., 1985). Entre estas respuestas se destaca la actividad de proteínas asociadas a membrana plasmática (PM), que actúan en la percepción de estímulos y transporte de solutos (Peer, 2011). Mostrando dos formas definidas de respuestas sistémicas: Resistencia sistémica adquirida (RSA) y Resistencia sistémica inducida (RSI), diferentes al de tipo elicitor (Van Loon et al., 1998). La respuesta sistémica RSA es inducida por patógenos, por incremento de ácido salicílico (AS) sintetizado endógenamente en la planta, siendo una molécula de señalización esencial en la vía de RSA (Métraux et al., 1990). Verhagen et al., (2004), manifiestan que RSI proporciona a la planta mayor capacidad de respuesta y frente a infecciones, sólo se activaría tras el contacto con el patógeno. La colonización de raíces por cepas no patogénicas PGPR, dan paso a RSI, siendo ésta estrategia efectiva contra el ataque de patógenos, combatiéndolos a través de un mecanismo de defensa dependiente ha Jasmonato/ Etileno (JA/ET) (Ton et al., 2002).

El mecanismo de respuesta del gen $\mathrm{Nprl}$ es dependiente de la ruta de AS. Van der Ent et al. (2009), manifiesta que la colonización en raíces de Arabidopsis thaliana por Pseudomonas fluorescens WCS417r dirigen la RSI, activando el factor de transcripción MYB72 generando una cascada de transducción de señales que activan $\mathrm{Nprl}$. Fueron escogidos genes que participan en distintas etapas de regulación fisiológica y mecanismo de defensa en plantas: Nprl (factor regulador a RSA dependiente de AS); Eirl (transportador de flujo de auxinas específico para raíces); Lox2 (lipoxigenasa que lleva a la biosíntesis de ácido jasmonico (AJ)); Tlp1 (pertenece a la familia de PR-5 de proteínas relacionadas a patógenos (PR), con actividad antifúngica).

Las investigaciones realizadas por el Laboratorio de Biotecnológica (INIA-La Platina) y Laboratorio de Microbiología Molecular y Biotecnología Ambiental (UTFSM), se logró seleccionar e identificar un nuevo aislado de Pseudomonas veronii R4, de la rizósfera de cultivares de viñedos "Thompson Seedless", de Santiago-Chile. Está rizobacteria posee actividad antagonista hacia el nematodo Xiphinema index., es productora de la auxina ácido indolil-3-acético (AIA), e incrementa el desarrollo de raíces adventicias en hojas de vid. El trabajo de investigación inició con la identificación de genes de defensa que se ven activados por la ruta de señalización para etileno, jasmonato, ácido salicílico y rutas directas de interacción en raíces. Para el efecto se postula el objetivo, analizar los cambios en la expresión de genes de defensa en vid "Thompson Seedless" como respuesta a $P$. veronii $\mathrm{R} 4$, empleando q-PCR.

\section{Materiales y métodos}

\section{Preparación del material vegetal}

Se empleó plántulas de "Thompson Seedless" crecidas en medio de cultivo Murashige y Skoog (MS; Murashige y Skoog, 1962) suplementado con sacarosa al $2 \%(\mathrm{w} / \mathrm{v})$, bajo condiciones controladas a: $200 \mu \mathrm{E} \mathrm{m}^{-2} \mathrm{~s}^{-1}$ con luz fluorescente; un fotoperiodo de $16 / 8$ horas; $25^{\circ} \mathrm{C}$ día/noche, cumpliendo con las siguientes características: $7 \mathrm{~cm}$ de altura; 6 hojas; raíces con $4 \mathrm{~cm}$ de longitud; obtenidas del Instituto de Investigaciones Agropecuarias, del Laboratorio de Biotecnología, (INIA-La Platina) Santiago de Chile.

\section{Preparación del inóculo $P$. veronii $\mathbf{R} 4$}

El aislado bacteriano fue incubado en $100 \mathrm{~mL}$ de caldo King B hasta alcanzar $\left(1.5 \times 10^{9}\right.$ células $\left.\mathrm{mL}^{-1}\right)$, tomando $50 \mathrm{~mL}$ del cultivo bacteriano, centrifugado a

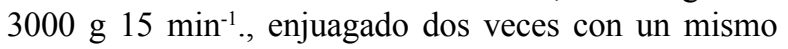
volumen de tampón PBS (pH 6.5) y re-suspendidas en la misma solución.

\section{Inoculación de $P$. veronii $\mathrm{R} 4$ en raíces de 'Thompson Seedless' y muestreo de tejidos}

Las plantas de 'Thompson Seedless' fueron retiradas de sus recipientes sin causar daños. Las raíces de 9 plantas fueron sumergidas en $P$. veronii $\mathrm{R} 4$ o el control tampón (PBS), por $5 \mathrm{~min}$, con 18 plantas en total, transferidas al medio de cultivo MS y $1 \mathrm{~g} \mathrm{~L}^{-1}$ de carbón activado. Se recolectó hojas y raíces de las tres plantas en los tiempos de muestreó, a $5 \mathrm{~min}, 6$ y 12 horas, posteriores a su inoculación, obteniendo un total 36 muestras. Las muestras fueron ubicadas individuamente en bolsas de papel aluminio, para ser tratadas con nitrógeno líquido. Todas las muestras fueron almacenadas a $-80^{\circ} \mathrm{C}$. 


\section{Extracción de ARN total y síntesis del ADN complementario}

De 100 mg de tejido vegetal: raíces u hojas, fueron maceradas en presencia de nitrógeno líquido, hasta la pulverización. El ARN total fue extraído de 36 muestras, empleando el kit "FavorPrepTM Plant Total RNA Mini Kit" (San Diego, California, U.S.A). Los ARN se visualizaron en geles de agarosa al 1\%, añadiendo bromuro de etidio, se midió su absorbancia mediante espectrofotometría óptica $(260 \mathrm{~nm})$. Las posibles contaminaciones con ADN genómico fueron eliminadas, con 10 unidades de DNasa libre de RNasa (New Englan Biolabs Inc., Ipswich, U.S.A). Los ARN fueron chequeados por PCR convencional, empleando una pareja de partidores para Ubiquitina. Partidor diseñado por el Laboratorio de Biotecnología INIA, VvUBQ1 sentido (5'-GTGGTGGTATTATTGAGCCATC-'3), anti-sentido (5'-GCCGCACTCTTGCTGAT-‘3).

La síntesis del ADNc, inició con $1 \mu \mathrm{g}$ de ARN total, empleando el kit de Transcriptasa reversa del virus Leukemia Murine Moloney (M-MLV RT) Reverse Transcriptase (Promega, Madison, WI, U.S.A). Al volumen de $10 \mu \mathrm{L}: 1,25 \mu \mathrm{L}$ de dNTPs $(10 \mathrm{mM}$ de $\mathrm{c} / \mathrm{u})$; $0,66 \mu \mathrm{L}$ Recombinant RNasin (25 unidades); $1 \mu \mathrm{L}$ de M-MLV RT (200 unidades); $5 \mu \mathrm{L}$ de buffer M-MMLV 5X (Promega. Madison. USA). La reacción de RTPCR se realizó bajo las siguientes condiciones: $42{ }^{\circ} \mathrm{C}$ por $60 \mathrm{~min} ., 95{ }^{\circ} \mathrm{C}$ por $5 \mathrm{~min}$ y $4^{\circ} \mathrm{C}$ por $15 \mathrm{~min}$ del ADNc, se eliminó todo remanente de ARN, mediante "Ribonuclease H" (Promega, USA). Se midió por espectrofotometría óptica la concentración final de las muestras del ADNc, finalmente fueron diluidas a una concentración de $100 \mathrm{ng} \mu \mathrm{L}^{-1}$ en $50 \mu \mathrm{L}$.

\section{Identificación y diseño de partidores para genes de importancia a RSI}

Desde la base de datos $A$. thaliana fue seleccionado los genes: (Lox2, Tlp1, Eir1, Npr1), activados para RSI, obteniéndose las secuencias nucleotídica y aminoácidos de cada gen a estudiar de esta especie (http://www. arabidopsis.org). La secuencia de aminoácidos de cada proteína se trasladó a la base de datos de Gramene, del genoma para Vitis vinifera 'Pinot Noir' (http://www. gramene.org/Vitis_vinifera/Info/Index) realizando la búsqueda por BLAST, obteniendo la información de Secuencia parcial del transcripto (EST), para todos los genes. A partir de los ESTs, se diseñaron partidores específicos, empleando el programa online Primer3Plus (http://www.bioinformatics.nl/cgi-bin/primer3plus/ primer3plus.cgi/) (Untergasser et al., 2007). Se diseñaron un total de 34 parejas de partidores $(\mathrm{Npr} 1=10$; Lox $2=5$; Tlp1=7; Eir1=12). El número de nucleótidos empleados fue de entre 16 a 27, para productos de PCR no mayor a 300 bp. La temperatura de alineamiento entre: 54 a 62
${ }^{\circ} \mathrm{C}$ y un grado de diferencia para cada pareja de partidor. Para determinar la eficiencia de los partidores se evaluaron 5 TM $\left(54 ; 56 ; 58 ; 60 ; 62^{\circ} \mathrm{C}\right)$, mediante PCR en gradiente bajo las siguientes condiciones: $95{ }^{\circ} \mathrm{C}$ por $3 \mathrm{~min} ; 30$ ciclos a $95^{\circ} \mathrm{C}$ por $30 \mathrm{seg} ; 54^{\circ} \mathrm{C}$ por $30 \mathrm{seg}$; $72{ }^{\circ} \mathrm{C}$ por $30 \mathrm{seg}$; la extensión final $72{ }^{\circ} \mathrm{C}$ por $5 \mathrm{~min}$. El producto de PCR fue separado por electroforesis en gel de agarosa al $1.50 \%$, teñido con bromuro de etidio. También se procedió a realizar la optimización para concentración y temperatura en los partidores seleccionados en q-PCR, verificando un solo producto de amplificación para la curva de Melting y las CT se encuentren en el rango dinámico.

\section{Clonaje y secuenciación del producto amplificado a cada gen en estudio}

Los productos amplificados de cada gen: Lox2, Tlp1, Eir1; Npr1, fueron clonados en el vector pGEM $₫-T$ (Promega U.S.A), siguiendo las instrucciones del fabricante, luego enviado a MACROGEN (http:// www.macrogen.com/eng/), obteniendo el resultado de la secuenciación. Se analizaron las secuencias de los EST por Vector NTI Advance ${ }^{\mathrm{TM}} 10$ (Invitrogen) y comparadas con las disponibles en el Gen-Bank usando BLASTN-NCBI.

\section{PCR cuantitativa en tiempo real (q-PCR)}

Los niveles de transcriptos fueron determinadas por q-PCR, para sus tres replicas biológicas y técnicas, empleando el equipo "StepOne Real Time PCR system" (Applied Biosystems, EEUU). Se usó el método de cuantificación relativa, mediante cuantificación del número de moléculas de los genes (Lox2, Eir1, Npr1, Tlp1) para cada muestra (cuantificación absoluta) y su normalización (obtención de la razón entre los genes y el número de moléculas de Ubiquitina y el factor de elongación EF1- $\alpha$ ), teniendo la curva estándar y regresión lineal de la eficiencia, bajo el programa de ciclaje de PCR recomendado por el fabricante. Las reacciones de q-PCR se llevaron a un volumen de 20 $\mu \mathrm{L}$, constituidos por $10 \mu \mathrm{L}$ de "FAST SYBR ${ }^{\circledR}$ Green PCR Master Mix (2X)" (Applied Biosystems, Foster, City, CA, USA) (Varnier et al., 2009), $2 \mu \mathrm{L}$ de ADNc (equivalente a $100 \mathrm{ng}$ de templado) y partidores con una concentración final de $300 \mathrm{nM} \mu \mathrm{L}^{-1}$ sentido y 300 $\mathrm{nM} \mu \mathrm{L}^{-1}$ anti-sentido y su temperatura de alineamiento y en $8 \mu \mathrm{L}$ de contenido de ADNc. La cuantificación relativa se realizó en razón del número de transcritos de genes (Eir1, Npr1, Lox2, Tlp1) y del gen constitutivo de referencia Ubiquitina. Los resultados corresponden a experimentos realizados por triplicado, con tres replicas técnicas para q-PCR. Se indica el promedio \pm desviación estándar DS, bajo el paquete utilitario Excel 2010 . 


\section{Resultados y discusión}

Obtención de ARN total de alta calidad

El empleo del kit "FavorPrepTM Plant Total RNA Mini Kit", mostro ser eficiencia para la obtención del ARN total, de tejidos (hojas y raíces), seleccionando muestras de calidad e integridad de ARN total para las 36 muestras analizadas. Se observó limpieza y definición de las bandas correspondientes a ( $\mathrm{ARNr}) 28 \mathrm{~S}$ y $18 \mathrm{~S}$ (Figura 1a y 1b).

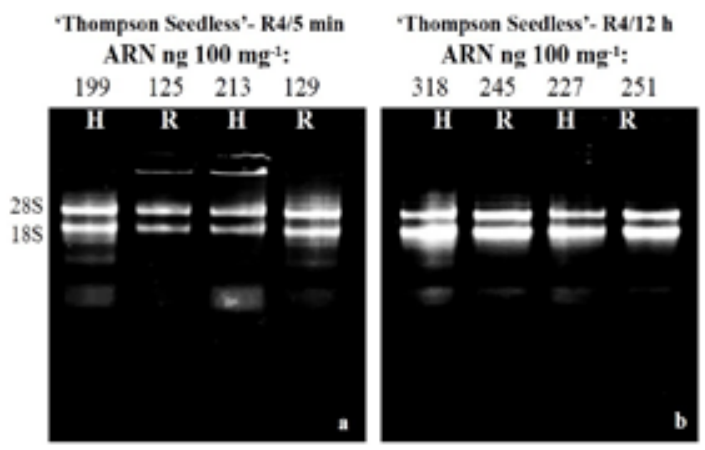

Figura 1. Extracción de ARN total de hojas y raíces de 'Thompson Seedless'. Inoculado con R4/5 min (a) y R4/12 min (b)

El rendimiento de extracción de ARN total en (ARN ng $100 \mathrm{mg}^{-1}$ ) de hojas (H) y raíces (R), de plantas expuestas por 5 min a $P$. veronii 4 (Figura 1a), plantas expuestas por $12 \mathrm{~h}$ a $P$. veronii $\mathrm{R} 4$ (Figura $1 \mathrm{~b}$ ). Índice de pureza (Abs 260/280) y análisis electroforético de ácidos nucleicos.

De $1 \mu \mathrm{L}$ de muestra el mayor promedio de concentración fue de $377 \mathrm{ng} 100 \mathrm{mg}^{-1}$ de tejido analizado. Las hojas muestreadas de plantas tratadas con PBS, se obtiene promedios de $226 \mathrm{ng} 100 \mathrm{mg}^{-1}$ ARN total y en plantas sometidas de $P$. veronii $\mathrm{R} 4$ de $245 \mathrm{ng} 100$ $\mathrm{mg}^{-1}$ ARN total. Mientras que en raíces muestreadas y expuestas a PBS y $P$. veronii $\mathrm{R} 4$ se encontraron valores de 245 y $189 \mathrm{ng} 100 \mathrm{mg}^{-1}$ de ARN total, respectivamente (Cuadro 1).

Al trabajar con el kit FavorPrepTM de extracción de $\mathrm{ARN}$, ofrece una alternativa rápida y fácil de ejecutar entre tres a cuatro horas, comparativamente con los protocolos de extracción de ARN total. Hao et al. (2012), realizaron extracciones de ARN total en Vitis berlandieri a base de tampones de extracción (CTAB; TRIS-HCL; EDTA; LiCl), que demandaron tiempos de trabajo de hasta dos días. Las concentraciones de ARN total de hojas muestreadas, oscilaron para el tampón PBS entre (181 a $274 \mathrm{ng} 100 \mathrm{mg}^{-1}$ ) y en presencia de P. veronii R4 (178 a $351 \mathrm{ng} 100 \mathrm{mg}^{-1}$ ). De raíces entre $\left(150\right.$ a $\left.377 \mathrm{ng} 100 \mathrm{mg}^{-1}\right)$ y $\left(123\right.$ a $\left.254 \mathrm{ng} 100 \mathrm{mg}^{-1}\right)$ respectivamente. Se deduce que los tejidos foliares
Cuadro 1. Concentración promedio de ARN total expresado en (ng $100 \mathrm{mg}^{-1}$ ), de tejido muestreado hojas (H) y raíces (R) en 'Thompson Seedless', expuestos por 5 min, 6 h y 12 h a $P$. veronii $R 4$ o el control PBS

\begin{tabular}{lcccc}
\hline & \multicolumn{2}{c}{ Sin bacteria } & \multicolumn{2}{c}{ P. veronii $\mathbf{R 4}$} \\
\hline \multicolumn{4}{c}{$\begin{array}{c}\text { Concentración de }\left(\mathbf{n g} \mathbf{1 0 0} \mathbf{~ m g}^{-1}\right) \\
\text { tejido de } \\
\text { muestreado }\end{array}$} \\
\hline & H & R & H & R \\
$5 \mathrm{~min}$ & 181 & 153 & 178 & 123 \\
$6 \mathrm{~h}$ & 222 & 377 & 205 & 189 \\
$12 \mathrm{~h}$ & 274 & 150 & 351 & 254 \\
Promedio & 226 & 227 & 245 & 189 \\
\hline
\end{tabular}

tuvieron mayor concentración de ARN total a diferencia de las raíces, pero ambos casos estas concentraciones fueron inferiores a las obtenidas por Morante et al. (2014), quienes lograron obtener 880 a $950 \mathrm{ug} \mathrm{g}^{-1} \mathrm{de}$ ARN total a partir de un gramo de cultivo de células en suspensión de Vitis vinifera cv. Gamay, al ajuste del protocolo con tampones constituidos de (TRIS-HCL; EDTA; $\mathrm{NaCl}$; CTAB).

Los protocolos permiten ajustar los tampones para aumentar la eficiencia de extracción de ARN, a diferencia de los kit de extracción que pierden su eficiencia para su empleo en diferentes tejidos y genotipos con presencia de polifenoles.

Selección y validación de los partidores para los genes (Lox2, Eir1, Npr1, Tlp1) y secuenciación del ADNc

La temperatura de alineamiento óptimo para cada partidor, fue determinada por PCR en gradiente, empleando como templado el ADNc de raíces y hojas. Una vez determinada la TM óptima de las 34 parejas de partidores fue seleccionado un partidor para cada

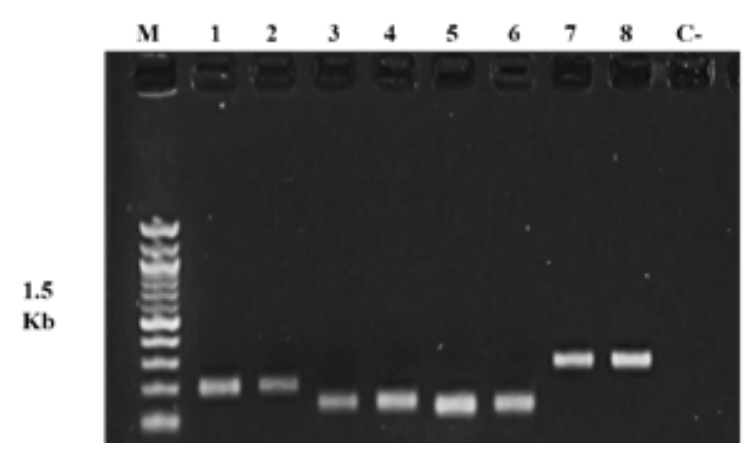

Figura 2. Recuperación de los productos amplificados para los genes: Npr1, Tlp1, Lox2, Eir1. Marcador estándar de peso molecular Fermentas $\mathbf{1 0 0}$ bp. Carril M; Carriles (1 y 2) gen Npr1; (3 y 4) gen Tpll; (5 y 6) gen Lox 2 ; (7 y 8$)$ gen Eir1. Carril C- (agua) 
gen (partidor 11, partidor 2, partidor 5, partidor 3), corroborando el tamaño de banda esperado (281 bp, 198 bp, 129 bp, 139 bp). Estas 4 parejas de partidores mostraron un solo amplicón, visualizadas en geles de agarosa (Figura 2).

Se confirmó el tamaño de sus amplicones de los genes (Lox2, Eir1, Npr1, Tlp1) por secuenciación, con la identidad del $100 \%$ de similitud a trabajos de análisis in silico, mostrando homologías con funciones putativas relevantes para la fisiología en Vitis vinífera, observadas en el GenBank del NCBI, para los ESTs en los genes estudiados (Cuadro 2).

El rendimiento de extracción de ARN total en (ARN ng $100 \mathrm{mg}^{-1}$ ) de hojas (H) y raíces (R), de plantas expuestas por 5 min a $P$. veronii $\mathrm{R} 4$ (A), plantas expuestas por $12 \mathrm{~h}$ a $P$. veronii $\mathrm{R} 4(\mathrm{~B})$. Índice de pureza (Abs 260/280) y análisis electroforético de ácidos nucleicos.

Los resultados obtenidos en este estudio fueron convincentes a la selección de genes, siendo específicos para el gen Lox2, que permitió diferenciar la activación transcripcional del gen, en el tejido muestreado de "Thompson Seedless". Feussner y Wasternack (2002), manifiestan que existen múltiples isoformas de LOX en una amplia gama de plantas y el caso de $A$. thaliana, al menos seis genes de LOX han sido caracterizados. La expresión del AtLoxl es estimulado por hormonas relacionadas a la respuestas adaptativas al estrés, tales como, ácido abscísico y metil jasmonato (Melan et al., 1993) y AtLox 2 ha sido identificado y relacionado en biosíntesis de jasmonato activado por heridas (Bell et $a l ., 1995)$. En este trabajo el diseño del partidor Lox2 fue específico para una isoforma, dentro de una amplia familia de los genes Lox. A diferencia Hao et al. (2012), diseñaron partidores sin especificar qué isoforma de la familia del gen LOX corresponde, para Vitis berlandieri tratadas con el hongo micorrizante Glomus intraradices. Caso contrario Zhang et al. (2006), desarrollan seis partidores para la familia de genes LOX (AdLoxl a AdLox6) para medir los niveles de expresión diferencial de LOX mediante q-PCR en Actinidia deliciosa (Kiwi).

\section{Patrón de estímulos de genes de defensa vegetales en presencia de $P$. veronii $\mathrm{R} 4$}

Respuesta del gen tipo Eir1. La aplicación de $P$. veronii R4 en "Thompson Seedless" estimuló la expresión del gen Eirl tras 5 min de exposición en raíces. Este resultado demuestra un gen de respuesta temprana, y que los niveles de expresión de Eirl van disminuyendo en el tiempo para 6 a 12 horas de interacción entre planta-rizobacteria. "Thompson Seedless" tratadas con R4 reflejaron niveles de expresión cuatro veces mayor en raíces, en comparación a hojas (Figura $3 \mathrm{a}$ y 3 b). No se detectaron cambios en los niveles de

Cuadro 2. Selección de partidores para los genes de defensa en RSI e identificación por homología de los productos amplificados con los ESTs en Vitis vinífera

\begin{tabular}{|c|c|c|c|c|c|c|}
\hline \multirow[b]{2}{*}{ Gen } & \multirow[b]{2}{*}{ Partidores } & \multicolumn{4}{|c|}{ Mejor HIT de BLASTN de NCBI } & \multirow{2}{*}{$\begin{array}{l}\text { Amplicón } \\
\text { (pares de } \\
\text { bases) }\end{array}$} \\
\hline & & Organismo & $\begin{array}{c}\text { Similitud } \\
(\%)\end{array}$ & $\begin{array}{l}\text { Accesión } \\
\text { GenBank }\end{array}$ & $\begin{array}{l}\text { Temperatura } \\
\text { de } \\
\text { alineamiento } \\
\left({ }^{\circ} \mathrm{C}\right) \\
\end{array}$ & \\
\hline $\operatorname{Lox} 2$ & $\begin{array}{l}\text { Sentido } \\
\text { 5'-TGATGGTCTCCTCCTGTGGG-3' } \\
\text { Anti-sentido } \\
\text { 5'-CTTGTTCGGATTTCGGTCCA-3' }\end{array}$ & $\begin{array}{l}\text { Vitis vinifera } \\
\text { cv Fujiminori. } \\
\text { Lipoxigenase } 2 \\
\text { (LOX2) RNAm }\end{array}$ & 100 & JQ281905.1 & 58 & 129 \\
\hline Eir1 & $\begin{array}{l}\text { Sentido } \\
\text { 5'-TGGAACATCAAAATGCCAACA-3' } \\
\text { Anti-sentido } \\
\text { 5'-CAAACACAAAGGGGACAATCC-3' }\end{array}$ & $\begin{array}{l}\text { Vitis vinifera. } \\
\text { (Transportador de } \\
\text { flujo de auxina); } \\
\text { (pin2, agr1, } \\
\text { wav6) }\end{array}$ & 100 & XM_002266023.1 & 60 & 281 \\
\hline Npr1 & $\begin{array}{l}\text { Sentido } \\
\text { 5'-TGGCTGATGCCCAGAGGAC-3' } \\
\text { Anti-sentido } \\
\text { 5'-AGTGCCGTTGCCCAGGTAT-3' }\end{array}$ & $\begin{array}{l}\text { Vitis vinifera } \\
\text { NPR1-like, } \\
\text { RNAm }\end{array}$ & 100 & XM_002281439.2 & 58 & 198 \\
\hline Tlp1 & $\begin{array}{l}\text { Sentido } \\
\text { 5'-CAAAGGGTCAGGCAAGTGTAGC-3' } \\
\text { Anti-sentido } \\
\text { 5'-GGCGAGTTGAAGGCAGAGC-3' }\end{array}$ & $\begin{array}{l}\text { Vitis vinifera, } \\
\text { thaumatina-like } \\
\text { protein, RNAm }\end{array}$ & 100 & XM_003634158.1 & 60 & 139 \\
\hline
\end{tabular}


expresión relativa del gen tipo Eirl en hojas, para plantas tratadas con R4 (Figura 3a). Se confirmó que las raíces expuestas al tampón PBS, reflejan niveles bajos o sin expresión alguna del gen Eirl para sus tejidos muestreados radiculares y foliares (Figura $3 \mathrm{a}$ y $3 b)$.

Los bajos niveles de expresión relativa del gen Eirl en hojas, responde a la funcionalidad específica del gen, denominado también como (pin2, agr1 o wav6). Este actúa en el transporte de flujo de auxinas, siendo específico para raíces (Figura 3a). La funcionalidad del gen Eirl en A. thaliana, corresponde a la familia de genes de plantas con similitudes a los transportadores de membranas bacterianas, expresado específicamente en raíces para el flujo de auxinas (Luschnig et al., 1998). La expresión relativa del gen Eirl responde de forma rápida al estímulo generado por la inoculación $P$. veronii R4 en raíces, es conocimiento a lo reportado por Effendi y Scherer (2011), que observaron el aumento en los niveles de expresión del gen pin2 al muestrear raíces de $A$. thalian expuesta a la auxina ANA durante $(0,30$ y 60 $\min$ ).

Los resultados indican que existe un beneficio bacteria-planta donde se requieren de componentes en señalización de auxinas y transporte en raíces. Se propone la activación de RSI, por el estímulo especifico del gen Eirl inducido por una bacteria no patogénica como $P$. veronii $\mathrm{R} 4$ a la colonización de raíces en 'Thompson Seedless'. Esto concuerda con Iavicoli et al. (2003) que indicaron que la presencia de la proteína EIR1 es necesaria para la protección de la raíz en el tratamiento por 2,4-DAPG, para activar la RSI en $A$. thaliana mediada por $P$. fluorescens CHA0.

Respuesta del gen tipo Npr1. En aplicación del tampón PBS y P. veronii R4 en raíces de "Thompson Seedless", los niveles de expresión del gen Nprl son constitutivos. Esto refleja una respuesta similar para ambos tejidos radiculares y foliares, no encontramos diferencias significativas en los niveles transcripcionales (Figura 3c y 3d), existiendo expresión basal de este mensajero tipo $\mathrm{Nprl}$ en ambas condiciones (R4 o PBS), para ambos tejidos muestreados.

Los niveles transcripcionales alcanzados por el mensajero de tipo $\mathrm{Nprl}$, indican que no existen diferencias significativas en hojas y raíces de 'Thompson Seedless' cuando fueron expuestas a $P$. veronii $\mathrm{R} 4$ o tampón PBS (Figura $3 \mathrm{c}$ y $3 \mathrm{~d}$ ). La respuesta al estímulo del gen tipo Nprl en 'Thompson Seedless' radicaría al tipo de inductor y planta que se trabaje, dando como resultado un mecanismo de respuesta variable para RSI. Spoel et al. (2003) observaron la activación de NPR1 después de la infección por el patógeno, y este bloquea en el citosol la expresión de genes sensibles a jasmonato, llevando a la supresión del gen Lox2 en A. thaliana. El gen Nprl de A. thaliana ha demostrado ser un factor regulador importante en la respuesta a RSA dependiente de ácido salicílico (AS) (Cao et al., 1994).

Respuesta del gen tipo Lox2. La aplicación de $P$. veronii $\mathrm{R} 4$ en raíces de "Thompson Seedless" generó cinco veces mayores niveles de expresión del gen Lox2 en hojas, con un aumento progresivo detectado hasta $12 \mathrm{~h}$ después de la inoculación, lo que produjo diferencias significativas frente a plantas tratadas con el tampón PBS (Figura 3e). Por lo contrario, los tejidos radiculares presentaron bajos niveles transcripcionales del gen Lox2, a pesar que procedían de las mismas plantas de donde se extrajeron las muestras de tejido foliar, no detectándose diferencias significativas entre las plantas tratadas con cepa R4 o tampón PBS.

Es importante indicar que existe una activación sistémica tras la inoculación de $P$. veronii $\mathrm{R} 4$ en raíces de "Thompson Seedless", que le confiere la expresión relativa del gen Lox2 en los tejidos alejados a donde se realizó su inoculación (Figura 3e y 3f). Esta observación permitió establecer la efectividad de RSI dirigida por R4 en "Thompson Seedless" confiriendo un estado de prealerta, concordando con lo reportado por Pozo et al. (2008) quienes detectaron que en plantas de $A$. thaliana tratadas con metil jasmonato (MeJa) y P. fluorescens WCS417 mostraron un patrón de expresión inducido del gen Lox2, dando paso a la imprimación por RSI. Verhagen et al. (2004) manifiestan que RSI proporciona a la planta mayor capacidad en responder rápida y eficientemente a una infección, pero que sólo se activaría tras el contacto con el patógeno.

Este mecanismo de respuesta del gen Lox2, dependerá mucho de la interacción del microorganismo benéfico-planta, para conferir la protección por RSI. Los niveles de expresión del gen tipo Lox2 se ven incrementados en las hojas de vid y disminuyen en raíces, esta diferencia podría estar asociada a la funcionalidad del gen lipoxigenasa Lox2. Esto difiere con Stein et al. (2008), quienes no observaron diferencias en la expresión del gen Lox2 en hojas de $A$. thaliana, cuando las raíces fueron expuestas al hongo micorrízico Piriformospora indica durante 0,3 y 6 días. De igual manera, Hao et al. (2012) no observaron cambios en la expresión del gen Lox, cuando plantas Vitis berlandieri fueron tratadas con el hongo micorrízico Glomus intraradices. Los resultado de esta investigación permitieron verificar que la activación de los genes de defensa Eirl y Lox2 
son estimulados $P$. veronii $\mathrm{R} 4$, que dan paso a RSI en "Thompson Seedless", confirmando la activación por la ruta de señalización vía jasmonato por Lox2 y una ruta directa por Eirl.

Respuesta del gen tipo Tlp1. Como se ilustra en la Figura 3G, la aplicación de $P$. veronii R4 en "Thompson Seedless", los niveles de expresión son constitutivos para el gen tipo Tlpl en hojas muestreadas, expresándose de forma constitutiva este gen, entre plantas tratadas con R4 o el tampón PBS. No obstante, hubo diferencias entre los niveles de expresión del gen Tlp1 en el tejido radicular por la aplicación de R4, hasta las $12 \mathrm{~h}$ después de la inoculación con $P$. veronii $\mathrm{R} 4$ con respecto al control PBS (Figura 3h).
Los niveles transcripcionales del gen Tlp1 no presentaron diferencias en hojas ( 5 min, 6 y 12 h), a diferencia de raíces, donde se observó un estímulo en los niveles transcripcionales del gen Tlpl en 12 horas después de la inoculación, esto se relaciona con la habilidad que tiene R4 en desarrollar el complejo de simbiosis y activar la RSI. Además, se observó que la expresión relativa de los genes de defensa Eir1, Lox2 y $T l p 1$, en 'Thompson Seedless', se ven estimulados en un solo tejido específico (foliar o radicular) (Figura $3 \mathrm{~g}$ y $3 \mathrm{~h}$ ), es concordante con lo publicado por León et al. (2005), quienes estudiaron raíces de $A$. thaliana colonizadas por P. fluorescens WCS417 no encontraron diferencia significativa en la expresión de AtTLP1 en hojas, pero si la inducción de AtTLP1 en raíces.

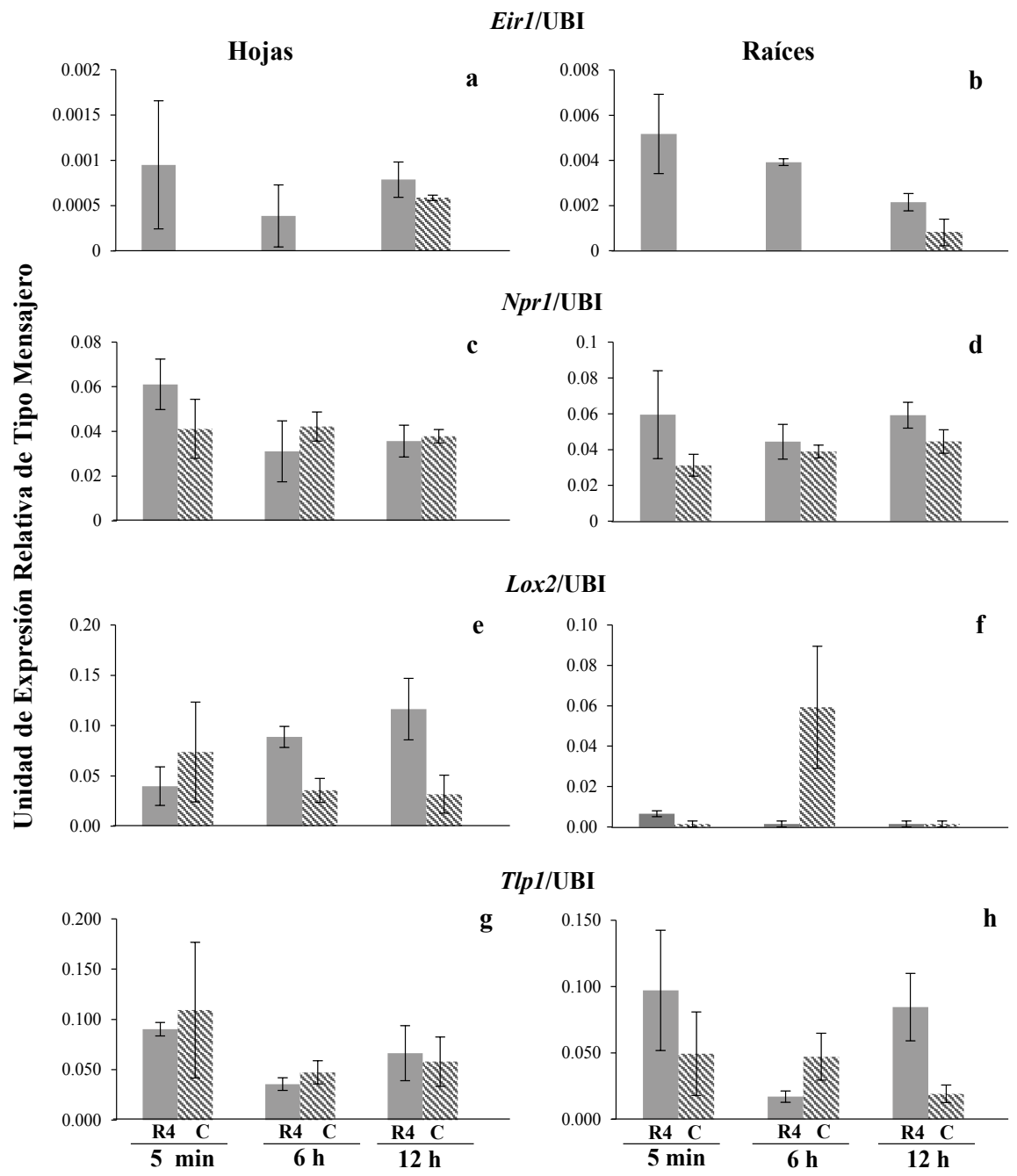

Figura 3. El estímulo de genes de respuesta al mecanismo de defensa en 'Thompson Seedless' de hojas muestreadas (a, c, e y g) y raíces muestreadas (b, $\mathrm{d}, \mathrm{f}$ y $\mathrm{h}$ ). Plantas tratadas con $P$. veronii (R4) o tampón PBS (c). La cuantificación relativa se realizó mediante la razón del número de transcritos de los genes (Eir1, Npr1, Lox2, Tlp1) y del gen constitutivo de referencia Ubiquitina. Se indica el promedio \pm DS 
El estímulo del gen Tlp1, es específica para raíces de "Thompson Seedless", en respuesta a la colonización de la rizobacteria $\mathrm{R} 4$, inducido por la vía del etileno (ET). Al estímular del gen Tlp1 en 'Thompson Seedless', se daría paso al mecanismo de protección para hongos necrotróficos y generar la actividad antimicrobiana en la raíz. Tlpl pertenece a la familia de los PR-5 de las proteínas relacionadas a patógenos PR, con actividad antifúngica y aumenta la resistencia a la infección por patógenos (Datta et al. 1999). Las raíces de la planta tienen la capacidad de percibir las señales que están presentes en la superficie de ella, y traducir estas señales en respuestas de defensas locales y sistémicas. El mecanismo de acción de los TLPs, relacionado con la defensa vegetal, está asociada a la capacidad de hidrolizar los $\beta-1,3$ glucanos presentes en la pared celular de los hongos (Grenier et al., 1999).

\section{Conclusiones}

$\mathrm{L}$ a aplicación de $P$. veronii R4 en "Thompson Seedless", ejerce un efecto sinérgico hacia la planta, brindando un efecto de imprimación, como consecuencia una activación rápida de las respuestas de los genes de defensas antes ser expuestas a un patógeno. Las raíces de "Thompson Seedless" expuestas a la cepa R4, estimulan la expresión de los genes Eir1, Lox2, Tlp1 por $5 \mathrm{~min}, 6$ y $12 \mathrm{~h}$, permitiendo establecer la efectividad de RSI dirigida por la cepa R4 en "Thompson Seedless" confiriendo un estado de prealerta.

\section{Agradecimientos}

$\mathrm{T}$ rabajo financiado por Biofrutales S.A. Consorcio y la CORFO-Chile otorgado 13CTI-21520-SP07. "Nuevas tecnologías de mejoramiento Genético especies frutales, desarrollo de nuevos cultivares de Vides y Frutales de Carozos tolerantes a hongos y virus".

\section{Bibliografía}

Bell, E., Creelman, BA. and Mullet, JE. 1995. A chloroplast lipoxygenase is required for wound induced jasmonic acid accumulation in Arabidopsis. Proceedings of the National Academy of Sciences 92: 8675-8679.

Cao, H., Bowling, SA., Gordon, AS. and Dong, X. 1994. Characterization of an Arabidopsis mutant that is non responsive to inducers of systemic acquired resistance. The Plant Cell 6: 1583-1592.
Datta, K., Velazhahan, R., Oliva, N., Ona, I., Mew, T., Khush, GS., Muthukrishnan, S. and Datta, SK. 1999. Overexpression of cloned rice thaumatinlike protein (PR-5) gene in transgenic rice plants enhances environmental friendly resistance to Rhizoctonia solani causing sheath blight disease. Theoretical and Applied Genetics 98: 1138-1145.

Effendi, Y. and Scherer, FE. 2011. Auxin bindingprotein1 (ABP1), a receptor to regulate auxin transport and early auxin genes in an interlocking system with PIN proteins and the receptor TIR1. Plant Signaling \& Behavior 6: 1-3.

Feussner, I. and Wasternack, C. 2002. The lipoxygenase pathway. Annual Review of Plant Biology 53: 275-297.

Grenier, J., Potvin, C., Trudel, J. and Asselin, A. 1999. Some thaumatin-like proteins hydrolyse polymeric beta-1,3-glucans. Plant Journal 19: 473-480.

Hao, Z., Fayolle, L., Tuinen, D., Chatagnier, O., Li, X., Gianinazzi, S. and Pearson, G. 2012. Local and systemic mycorrhiza-induced protection against the ectoparasitic nematode Xiphinema index involves priming of defence gene responses in grapevine. Journal of Experimental Botany 56: 1-16.

Iavicoli, A., Boutet, E., Buchala, A. and Metraux, J. 2003. Induced systemic resistance in Arabidopsis thaliana in response to root inoculation with Pseudomonas fluorescens CHA0. Molecular Plant Microbe Interactions 16: 851-8.

Kortekamp, A. 2006. Expression analysis of defencerelated genes in grapevine leaves after inoculation with a host and a non-host pathogen. Plant Physiology and Biochemistry 44: 58-67.

León, KM., Verhagen, BW., Keurentjes, JJ., Van Pelt, JA., Rep, M., Van Loon, LC. and Pieterse, MJ. 2005. Colonization of the Arabidopsis rhizosphere by fluorescent Pseudomonas spp. activates a root specific, ethylene-responsive PR-5 gene in the vascular bundle. Plant Molecular Biology. 57: 731748.

Luschnig, C., Gaxiola, RA., Grisafi, P. and Fink, GR. 1998. EIR1, a root-specific protein involved in auxin transport, is required for gravi-tropism in Arabidopsis thaliana. Genes Development 12: 2175-2187.

Morante, J., Sellés, S., Martínez, A., Martínez, MJ., Luque, I., and Bru, R. 2014. RNA isolation from loquat and other recalcitrant woody plants with high quality and yield. Analytical Biochemestry 452: 46-53.

Melan, MA., Dong, XN., Endara, ME., Davis, KR., Ausubel, FM. and Peterman, TK. 1993. An Arabidopsis thaliana lipoxygenase gene can be induced by pathogens, abscisic acid, and methyl 
jasmonate. Plant Physiology 101: 441-450.

Métraux, JP., Signer, H., Ryals, J., Ward, E., Wyss-Benz, M., Gaudin, J., Raschdorf, K., Schmid, E., Blum, W. and Inverardi. B. 1990. Increase in salicylic acid at the onset of systemic acquired resistance in cucumber. Science 250: 1004-1006.

Murashige, T. and Skoog, F. 1962. A revised medium for rapid growth and biomass assays with tobacco tissue cultures. Plant Physilogy 15: 473-497.

Parker, CA., Rovira, AD., Moore, KJ. and Wong, TW. 1985. Ecology and mangement of soilborne planta pathogens. The American Phytopathological Society. St. Paul, Minnesota, USA. 358 p.

Peer, WA. 2011. Plasma membrane protein trafficking. The Plant Plasma Membrane, Plant Cell Monographs, eds. Murphy A.S., W. A. Peer, B. Schulz (Springer, Berlin). 19: 31-56.

Pozo, MJ., Van Der Ent, S., Van Loon, LC. and Pieterse, MJ. 2008. Transcription factor MYC2 is involved in priming for enhanced defense during rhizobacteria-induced systemic resistance in Arabidopsis thaliana. New Phytologist 180: 511523.

Somers, E. and Srinivasan, M. 2004. Rhizosphere bacterial signalling: a love parade beneath our feet. Critical Reviews in Microbiology 30: 205-240.

Stein, E., Molitor, A., Kogel, KH. and Waller, F. 2008. Systemic resistance in Arabidopsis conferred by the mycorrhizal fungus Piriformospora indica requires jasmonic acid signaling and the cytoplasmic function of NPR1. Plant Cell Physiologi 49: 17471751.

Spoel, HS., Koornneef, A., Claessens, SM., Korzelius, JP., Van Pelt, JA., Mueller, MJ., Buchala, AJ., Métraux, JP., Brown, R., Kazan, K., Van Loon, LC., Dong, X. and Pieterse, MJ. 2003. NPR1 modulates cross-talk between salicylate and jasmonate dependent defense pathways through a novel function in the cytosol. The Plant Cell 15: $760-770$.
Ton, J., Van Pelt, JA., Van Loon, LC. and Pieterse, MJ. 2002. Differential effectiveness of salicylatedependent and jasmonate/ethylene-dependent induced resistance in Arabidopsis. Molecular Plant-Microbe Interactions 15: 27-34.

Van Loon, LC., Bakker, PA. and Pieterse, CM. 1998. Systemic resistance induced by rhizosphere bacteria. Annual Review Phytopathology 36: 453483.

Van der Ent, S., Van Hulten, M., Pozo, MJ., Czechowski, T., Udvardi, MK., Pieterse, MJ. and Ton, J. 2009. Priming of plant innate immunity by rhizobacteria and $\beta$-aminobutyric acid: differences and similarities in regulation. New Phytologist 183: 419-431.

Varnier, AL., Sanchez, L., Vatsa, P., Boudesocque, L., Garcia, A., Rabenoelina, F., Sorokin, A., Renault, J., Kauffmann, S., Pugin, A., Clement, C., Baillieul, F. and Dorey, S. 2009. Bacterial rhamnolipids are novel MAMPs conferring resistance to Botrytis cinerea in grapevine. Plant Cell and Environment 32: 178-193.

Verhagen, BW., Glazebrook, J., Zhu, T., Chang, HS., Van Loon, LC. and Pieterse, MJ. 2004. The transcriptome of rhizobacteria-induced systemic resistance in Arabidopsis. Molecular Plant Microbe Interactions 17: 895-908.

Untergasser, A., Nijveen, H., Rao, X., Bisseling, T., Geurts, R. and Leunissen, AM. 2007. Primer3Plus, an enhanced web interface to Primer. Nucleic Acids Research 35: 71-74.

Zhang, B., Chen, K., Bowen, J., Allan, A., Espley, Karunairetnam, RS. and Ferguson, I. 2006. Differential expression within the LOX gene family in ripening kiwifruit. Journal of Experimental Botany 57: 3825-3836. 